\title{
Folic acid-conjugated amphiphilic alternating copolymer as a new active tumor targeting drug delivery platform
}

This article was published in the following Dove Press journal:

Drug Design, Development and Therapy

15 December 2016

Number of times this article has been viewed

\author{
Xia $\mathrm{Li}^{\prime}$ \\ Myron R Szewczuk ${ }^{2}$ \\ Cecile Malardier-Jugroot' \\ 'Department of Chemistry and \\ Chemical Engineering, Royal Military \\ College of Canada, ${ }^{2}$ Department of \\ Biomedical and Molecular Sciences, \\ Queen's University, Kingston, ON, \\ Canada
}

Abstract: Targeted drug delivery using polymeric nanostructures is an emerging cancer research area, engineered for safer, more efficient, and effective use of chemotherapeutic drugs. A pH-responsive, active targeting delivery system was designed using folic acid functionalized amphiphilic alternating copolymer poly(styrene-alt-maleic anhydride) (FA-DABA-SMA) via a biodegradable linker 2,4-diaminobutyric acid (DABA). The polymeric template is $\mathrm{pH}$ responsive, forming amphiphilic nanostructures at $\mathrm{pH} 7$, allowing the encapsulation of hydrophobic drugs on its interior. Moreover, the structure is stable only at neutral $\mathrm{pH}$ and collapses in the acidic tumor microenvironment, releasing drugs on-site from its core. The delivery vehicle is investigated using human pancreatic PANC-1 cancer cells and RAW-Blue ${ }^{\mathrm{TM}}$ mouse macrophage reporter cell line, both of which have overly expression of folic acid receptors. To trace the cellular uptake by both cell lines, curcumin was selected as a dye and drug mimic owing to its fluorescence nature and hydrophobic properties. Fluorescent microscopy of FA-DABA-SMA loaded with curcumin revealed a significant internalization of the dye by human pancreatic PANC-1 cancer cells compared to those with unfunctionalized polymers (SMA). Moreover, the FA-DABA-SMA polymers exhibit rodlike association specific to the cells. Both empty SMA and FA-DABA-SMA show little toxicity to PANC-1 cells as characterized by WST-1 cell proliferation assay. These results clearly indicate that FA-DABA-SMA polymers show potential as an active tumor targeting drug delivery system with the ability to internalize hydrophobic chemotherapeutics after they specifically attach to cancer cells.

Keywords: functionalized copolymers, folic acid receptors, curcumin, enhanced hydrophobic drug delivery, improved cellular uptake

\section{Introduction}

Conventional chemotherapy is one of the most common treatments for cancer; however, current technologies suffer from limitations such as poor aqueous solubility, which causes elevated toxicity, lack of selectivity toward cancer cells, and multiple drug resistance against treatments. ${ }^{1}$ The application of nanotechnology to deliver drugs to tumor cells is an attractive alternative. It allows drug to be delivered to cancer cells specifically with prolonged circulation time and with a controlled drug release. ${ }^{2-4}$ In addition, controlled drug delivery improves bioavailability by preventing premature degradation and enhancing uptake, as well as by maintaining drug concentration and release rate within the therapeutic window, while reducing side effects by targeting cancer cells..$^{5-7}$ Commonly, there are three levels of targeting strategies using polymeric templates, including passive, active, and stimuli-responsive targeting. Passive targeting, also known as enhanced permeability and retention (EPR) effect, takes 
advantage of the leaky vascular solid tumor structures with poor drainage. This allows particles of a certain size to enter and accumulate in the tumor tissues. ${ }^{7,8}$ Once the drug is unloaded, the biocompatible polymers would clear through the excretory system. Despite the ability of the EPR effect to improve the accumulation of macromolecules, there are a few barriers to the EPR effect including high interstitial fluid pressure in tumor tissues, ${ }^{7}$ layers of tissue penetration that is demanded for therapeutic macromolecules, and liver and spleen accumulation of these particles. As a result, additional targeting strategies are required to enhance the distribution of the therapeutic macromolecules. Active targeting mechanisms utilize tumor-specific receptor ligands to achieve a degree of specificity, and therefore it is used as a promising complementary strategy to EPR effect. Targeting molecules include carbohydrates, antibodies, and ligands where their receptors are overly expressed in tumor tissues but are limited in healthy cells. Active targeting would not only improve therapeutic efficiency but also enable reduction of the amount of drug that must be administered to achieve a therapeutic response, thus minimizing negative side effects. ${ }^{2,9-11}$ Finally, stimuli-responsive delivery systems are designed in response to external stimuli (ie, $\mathrm{pH}$, light, and magnetic field), so that the drug release is triggered only at the desired time and location. When exposed under external stimuli, the polymers will undergo physiochemical structural changes, and therefore lose the well-defined nanoarchitectures releasing drugs directly onto the tumor cells. Among the external stimuli, $\mathrm{pH}$ gradients have been widely used for controlled release, relying on the abnormally low $\mathrm{pH}$ of endosomes or tumor tissues compared with healthy tissues. ${ }^{12-15}$

The present study describes a strategy to develop a "smart" drug carrier with all three delivery strategies. In particular, alternating copolymer poly(styrene-alt-maleic anhydride) (SMA) was chosen as the polymeric template (Figure 1A). Amphiphilic alternating copolymers can be structurally very close to biological systems since the alternating pattern of hydrophilic and hydrophobic groups
A

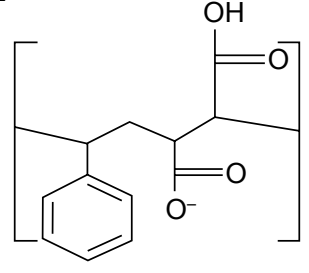

B

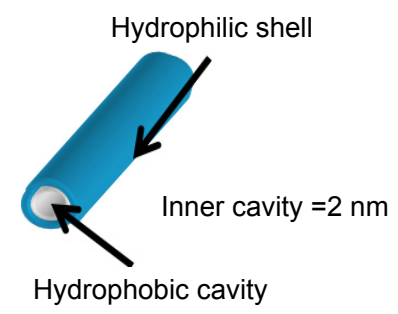

Figure I (A) Chemical structure of SMA; (B) SMA self-assembly at $\mathrm{pH} 7$ in aqueous solution.

Abbreviation: SMA, poly(styrene-alt-maleic anhydride). provides uniform interaction along the polymer chains within a nanoarch formed by self-assembly. Indeed, SMA can selfassemble into very ordered nanoarchitectures with cavities as small as $3 \mathrm{~nm}$, resulting in increased volume-to-surface ratio that would further increase the delivering efficiency owing to the EPR effect (Figure 1B). The self-assembly process, only observed at neutral $\mathrm{pH}$, is linked to the linearity of the polymer chain, reducing the entropic cost of chain interaction. The obtained nanostructure is either nanotubes or nanosheets depending on the molecular weight of the polymer, as described in the previous studies. ${ }^{5,6}$ The linearity observed only at neutral $\mathrm{pH}$ originates from a strong hydrogen bond formed within the hydrophilic groups of SMA when one acid group is hydrolyzed. The self-assembled structures characterized by transmission electron microscopy are shown as a function of molecular weight in Figure 2. To implement the active delivery, folic acid, a commonly used targeting molecule was linked to SMA polymers on its hydrophilic exterior via a biological linker to actively bind to tumor sites. The biological linker was selected using a careful and complete characterization of the functionalized polymer using molecular modeling (such as density functional theory). ${ }^{16}$ This study ensured that the functionalization of the polymer with the biological linker and folic acid would not affect the linearity of the polymer at $\mathrm{pH} 7$ (Figure 3). This property is crucial for an unaltered delicate self-assembly process, while preserving the $\mathrm{pH}$ sensitivity of the polymer. ${ }^{16}$

The active targeting using FA originates from folic acid receptors overly expressed in various cancer cells including malignancies of the pancreas, ovary, brain, kidney, breast, and lung. ${ }^{15,16}$ The binding efficiency between folate and its receptors is very high $\left(\mathrm{K}_{\mathrm{D}} \sim 10 \mathrm{~m}\right)$, and the folate conjugates will go through cellular uptake via receptor-mediated endocytosis. ${ }^{15-21}$ The linker was added to increase the flexibility between targeting agents and drug carrying unit so that the steric hindrance effect would be reduced and the reactivity of the folic acid-modified SMA drug carrier would be increased. Lastly, owing to the $\mathrm{pH}$-responsive nature of SMA, drugs will be released once the carriers reach the tumor sites with lowered $\mathrm{pH}$ environment, causing the system to switch from the "off" state to the "on" state (Figure 4).

This study group has previously reported the synthesis and complete experimental and theoretical characterization of the above-mentioned delivery vehicle FA-DABA-SMA. ${ }^{16}$ At neutral $\mathrm{pH}$, the functionalized polymers form stable nanoparticles with a hydrodynamic radius of $144 \mathrm{~nm}$ and collapse at lower or higher $\mathrm{pH}$, confirming FA-DABA-SMA as a good candidate for a $\mathrm{pH}$-responsive targeted drug delivery vehicle (Figure 5). The linker 2,4-diaminobutyric 

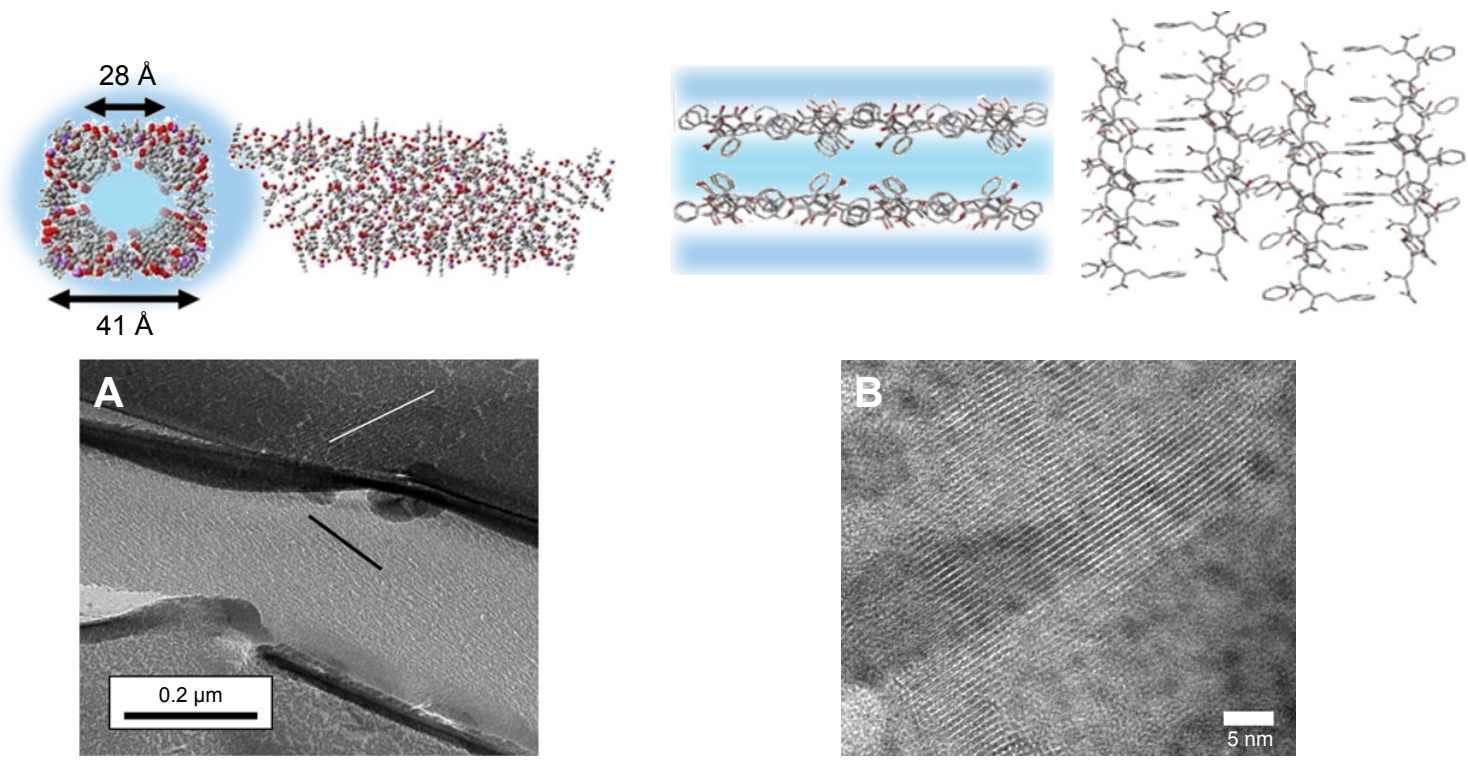

$4 \mathrm{kDa}$

$350 \mathrm{kDa}$

Figure 2 Molecular modeling and transmission electron microscopy characterization of the self-assembled structure of SMA at (A) low molecular weight and (B) high molecular weight. Adapted with permission of Taylor \& Francis, from Molecular Simulation, Characterization of a novel self-association of an alternating copolymer into nanotubes in solution, Malardier-Jugroot C, van de Ven TGM, Whitehead MA, 3I, 2-I, 2005; permission conveyed through Copyright Clearance Center, Inc., ${ }^{45}$ and adapted from Chemical Physics Letters, 636, McTaggart M, Malardier-Jugroot C, Jugroot M, Self-assembled biomimetic nanoreactors I: polymeric template, 206-220, Copyright (2015), with permission from Elsevier. ${ }^{46}$

Abbreviation: SMA, poly(styrene-alt-maleic anhydride).

acid (DABA) was selected to improve the accessibility of the ligand. The biodegradable property of DABA and the fact that the linkage between folic acid and SMA through DABA conserved the $\mathrm{pH}$ responsiveness of FA-DABASMA confirmed its suitability as a linker. The results from cell studies are reported after incubating FA-DABA-SMA to two cell lines such as RAW-Blue macrophage cell lines and human pancreatic PANC-1 cancer cells. Curcumin was selected as a hydrophobic drug mimic and a fluorescent marker to be introduced to the hydrophobic core of FA-DABA-SMA. Curcumin is the extract of the natural ingredient of Curcuma longa (turmeric). ${ }^{23}$ Traditionally, it has been used in the practice for the treatment of common

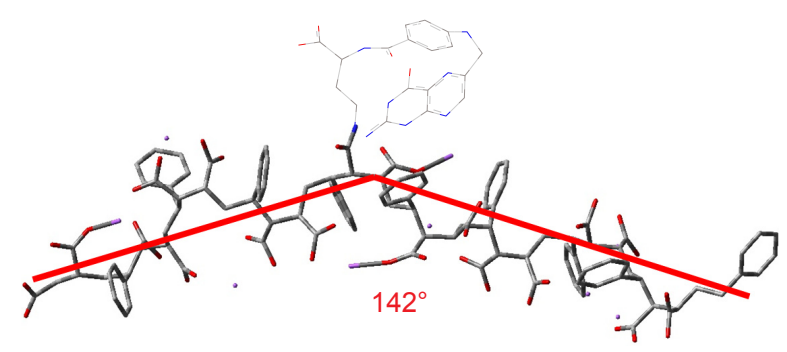

Figure 3 FA-DABA-PSMA oligomer at $\mathrm{pH} 7$ at \#I carboxylic acid using ONIOM model: central trimer optimized to DFT, outer two to PM6. Adapted with permission from Biophy Chem, 214-215, Li X, McTaggart M, Malardier-Jugroot C, Synthesis and characterization of a $\mathrm{pH}$ responsive folic acid functionalized polymeric drug delivery system, 17-26. Copyright (2016), with permission from Elsevier. ${ }^{16}$

Abbreviations: DFT, density functional theory; PM6, complete parameter optimization. cold, skin diseases, wound healing, and inflammation. ${ }^{23,24}$ Recent research has confirmed that curcumin possesses antioxidant, anti-inflammatory, antibacterial, and antiamyloid properties and suppresses proliferation of a wide variety of tumor cells such as pancreatic cancer, multiple myeloma, and colorectal cancer. ${ }^{25-29}$ In addition, curcumin could act as a fluorescent probe for tracing drug uptake in cell studies since the compound exhibits fluorescence maxima at around $540 \mathrm{~nm}$ after excitation at $420 \mathrm{~nm} \cdot{ }^{25,30-33}$ However, its limited solubility and bioavailability prevent its usage. Presently, many research groups work to enhance the solubility and pharmacokinetic property of native curcumin by encapsulation through either a mechanical or a chemical process. The

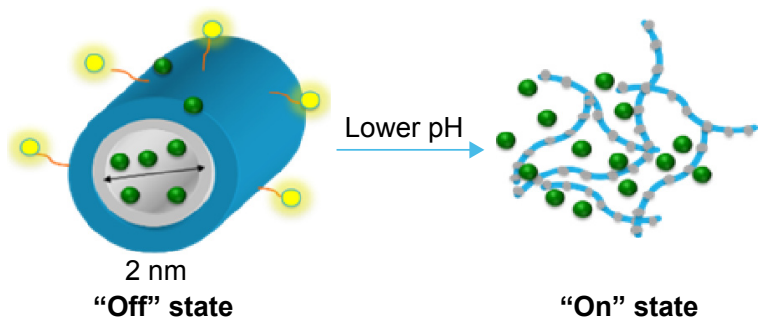

Figure 4 Schematic representation of FA-DABA-SMA in its "off" state and "on" state.

Notes: Yellow spheres represent folic acid molecules, green represents hydrophobic drugs, blue shows the hydrophilic part of the polymers, and finally, the gray is the hydrophobic part of the polymer. Adapted with permission from Biophy Chem, 214-2I5, Li X, McTaggart M, Malardier-Jugroot C, Synthesis and characterization of a $\mathrm{pH}$ responsive folic acid functionalized polymeric drug delivery system, 17-26. Copyright (2016), with permission from Elsevier. ${ }^{16}$ 

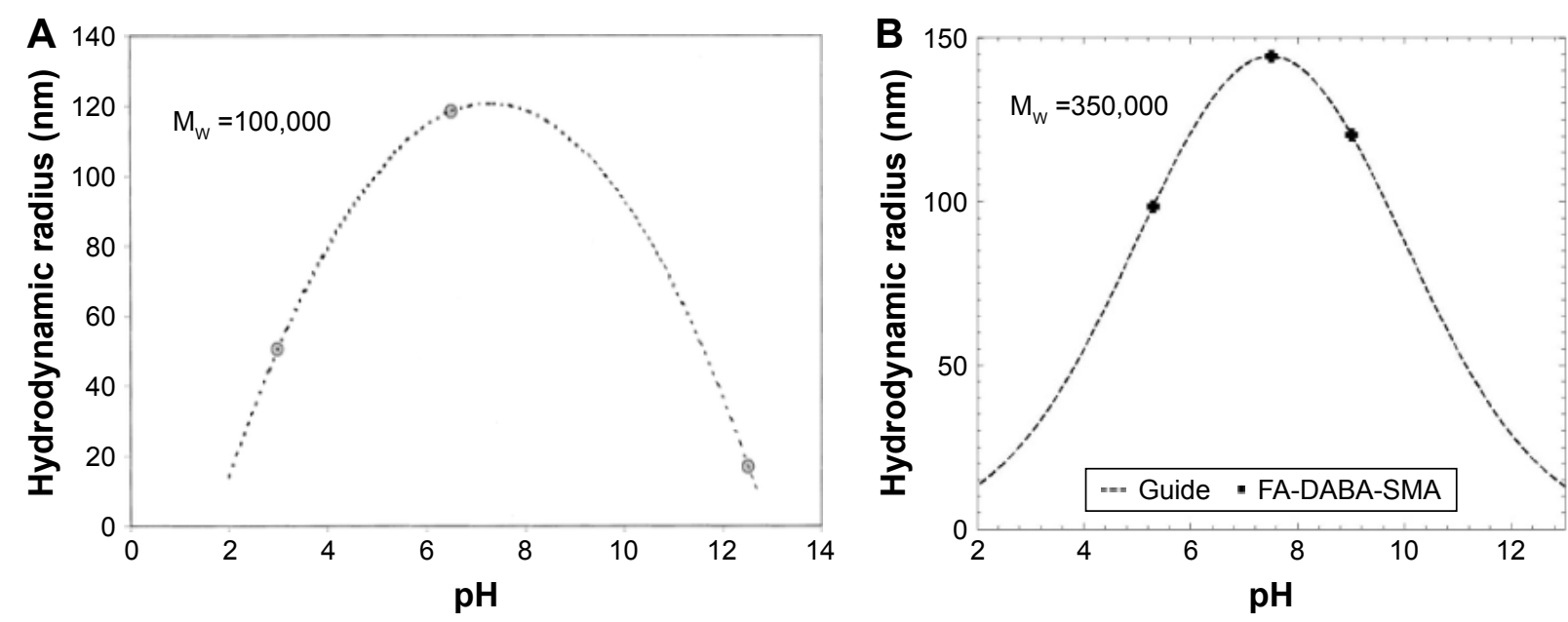

Figure 5 Dynamic light scattering results of (A) pure 0.05 wt\% SMA solution and (B) I wt\% PSMA-DABA-FA with mean zeta potential of -39.89 mV.

Notes: The presented line in the graph is a guide for the eyes. Adapted with permission from Biophy Chem, 2I4-2I5, Li X, McTaggart M, Malardier-Jugroot C, Synthesis and characterization of a $\mathrm{pH}$ responsive folic acid functionalized polymeric drug delivery system, 17-26. Copyright (2016), with permission from Elsevier. ${ }^{16}$

Abbreviations: DABA, biodegradable linker 2,4-diaminobutyric acid; FA, folic acid; SMA, poly(styrene-alt-maleic anhydride).

mechanical process utilizes the solution-enhanced dispersion technique by supercritical $\mathrm{CO}_{2}$ to produce curcumin nanoparticles. ${ }^{34,35}$ Although the method is able to manipulate the properties of the obtained nanoparticles by controlling the parameters of the synthesis process including the flow rate of curcumin solution, precipitation pressure, concentration of curcumin solution, and precipitation temperature, the experimental setups are complicated, and the products are not always in aqueous forms. Alternatively, chemical approaches employ polymeric nanocarrier systems such as liposomes, chitosan nanoparticles, micelles, and so on to solubilize curcumin in the core of the nanostructures. ${ }^{26,28,36-40}$ Although the encapsulation processes are usually simple, organic solvents are often used, which could introduce undesired toxicity. This study used FA-DABA-SMA as the synthesized drug carrier to deliver curcumin. The encapsulation process is chemical free as curcumin powders diffuse into the hydrophobic core over time. The delivery and release process will be noninvasive as the curcumin drug carrier will be circulated in the bloodstream, and the release is triggered by $\mathrm{pH}$ change in the microenvironment of the cancer cells.

In general, drugs can be incorporated into the delivery vehicles through covalent and noncovalent interactions. In the former, anticancer drugs are linked to the polymer through covalent bonds forming "prodrug", which will be converted into their active forms upon delivery. However, the process of getting the polymer-drug conjugation approval is slow, and many polymer-drug conjugates show unexpected release behavior and side effects in clinical testing. ${ }^{8}$ Noncovalent interactions, on the other hand, utilize hydrogen bonding, $\pi-\pi$ stacking, and ionic interactions to encapsulate drugs in the interior. ${ }^{41,42}$ In this study, the hydrophobic interior of SMA template cavity will encapsulate hydrophobic curcumin through diffusion and release the drug directly without prodrug conversion upon reaching the tumor site.

The uptake of curcumin in pancreatic PANC-1 cancer and RAW-Blue macrophage cell lines was studied using fluorescent microscopy. The cell viability using FA-DABA-SMA and curcumin-encapsulated FA-DABA-SMA was examined using the cell proliferation WST-1 assay. ${ }^{44}$ The results from this study show the potential of using FA-DABA-SMA as a targeted hydrophobic drug delivery vehicle.

\section{Materials and methods \\ Cell lines}

The PANC-1 (American Type Culture Collection, Manassas, VA, USAATCC ${ }^{\circledR}$; CRL-1469 ${ }^{\mathrm{TM}}$ ) cells are a human pancreatic ductal epithelial carcinoma cell line. RAW-Blue ${ }^{\mathrm{TM}}$ (InvivoGen, San Diego, CA, USA) cells are derived from the murine RAW 264.7 macrophages. Both cell lines overly express folic acid receptors on the cell surfaces. Cells were grown in media containing Dulbecco's Modified Eagle's Medium (1×; Gibco, Rockville, MD, USA) supplemented in 10\% fetal calf serum (HyClone Laboratories, Inc., Logan, UT, USA) and $5 \mu \mathrm{M} / \mathrm{mL}$ Plasmocin (InvivoGen) in a $5 \%$ $\mathrm{CO}_{2}$ incubator at $37^{\circ} \mathrm{C}$.

When the cells reached $80 \%$ confluency, they were incubated with SMA or FA-DABA-SMA, each loaded with curcumin at four different concentrations of $0.3,1,3$, and $10 \mu \mathrm{m}$. The cells were incubated for 12 hours before analysis by fluorescent microscopy.

The FA-DABA-SMA particles were synthesized following previous published protocols. ${ }^{16}$ 


\section{Curcumin encapsulation}

Curcumin was loaded to SMA and FA-DABA-SMA polymers through physical entrapment. Briefly, excess curcumin was added to polymer stock solutions at $54 \mu \mathrm{m}$ concentration. The solution was allowed to settle and was centrifuged at $4,000 \mathrm{rpm}(2500 \times \mathrm{g})$ for 7 minutes to remove the remaining curcumin from the solution. Curcumin-loaded polymers were then diluted to four different concentrations of $0.3,1,3$, and $10 \mu \mathrm{m}$. The curcumin-loaded SMA was characterized using Tecan M1000 Pro plate reader (Tecan Group Ltd, Männedorf, Switzerland) in 96-well microplates.

\section{Fluorescent microscopy}

The cellular uptake of curcumin was visualized using a fluorescent microscope. Briefly, $5 \times 10^{4}$ RAW-Blue or PANC- 1 cells were seeded in 24-well plates on $12 \mathrm{~mm}$ circular glass cover slides in Dulbecco's Modified Eagle's Medium containing 10\% fetal bovine serum at $37^{\circ} \mathrm{C}$ in $5 \% \mathrm{CO}_{2}$ overnight to allow cells to attach to slides. Cells were treated with SMA, FA-DABA-SMA, or untreated as a control for overnight at $37^{\circ} \mathrm{C}$. Subsequently, the cell culture media was removed, and the cells on circular glass slides were placed on $4 \mu \mathrm{L}$ of fluorescence mounting medium (DAKO, Agilent Technologies, Santa Barbara, CA, USA). The fluorescent images were taken using a Zeiss M2 Imager epifluorescent microscopy (Carl Zeiss AG, Oberkochen, Germany) ( $40 \times$ objective, at $200 \times$ and $400 \times$ magnification).

\section{WST-I assay}

The WST-1 assay was used as a measure of cell viability based on the reduction of a tetrazolium compound to a soluble derivative. ${ }^{43,44}$ The absorbance recorded at $420 \mathrm{~nm}$ is directly proportional to the number of living cells in culture. At $80 \%-90 \%$ confluence, cells were added to 96-well microplates at a density of 5,000 cells per well and incubated at $37^{\circ} \mathrm{C}$ overnight. They were then exposed to increasing concentrations of indicated polymer treatments or left untreated as controls for 24, 48, and 72 hours. About $100 \mu \mathrm{L}$ of WST-1 reagent (Roche Diagnostics Division de Hoffman La Roche Limitée, Laval-des-Rapides, QC, Canada), diluted 1:10 in culture medium, was added to the wells for 2 hours prior to reading of absorbance at $420 \mathrm{~nm}$ at each time point. Cell viability was presented as a percentage of control using GraphPad Prism software (GraphPad Software, Inc., La Jolla, CA, USA). The following formula was used to determine cell viability as a percent of control for each time point and treatment:

\section{(Absorbance of cells in a given concentration of drug) - (Media absorbance) \\ (Absorbance of cells alone)-(Media absorbance)}

\section{Results and discussion}

To confirm the increased solubility of encapsulated curcumin in SMA aqueous solution as compared with its solubility in water, fluorescent spectroscopy was performed on aqueous solutions of curcumin and SMA-curcumin. First, Figure 6 shows that both spectra exhibit emission maxima at around $540 \mathrm{~nm}$ with excitation wavelength at $420 \mathrm{~nm}$, confirming the fluorescent properties of curcumin as a probe in the cells. Second, the emission spectrum of curcumin-loaded SMA

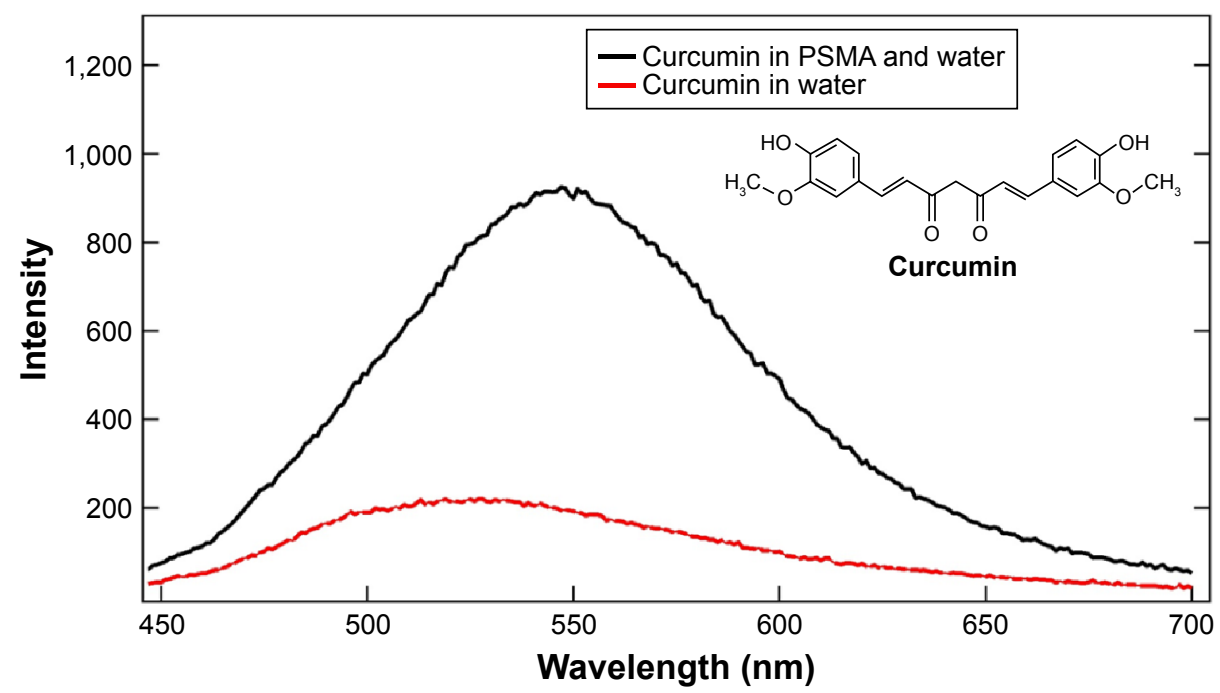

Figure 6 Chemical structure of curcumin and fluorescence intensity of curcumin in water and when encapsulated in SMA polymers (PSMA) (I\% wt to water) at excitation wavelength $420 \mathrm{~nm}$.

Abbreviation: SMA, poly(styrene-alt-maleic anhydride) 
shows a rapid increase in maxima intensity, indicating the enhanced solubility of curcumin in SMA and confirming that the polymers could act as delivery templates for curcumin.

The cellular uptake of curcumin-loaded SMA and FADABA-SMA was visualized by the intrinsic fluorescence of curcumin using fluorescence microscopy. Figure 7 shows the fluorescent images of curcumim-loaded SMA in RAW-Blue macrophage cells (Figure 7Aa-Ad) and PANC-1 pancreatic cancer cells (Figure $7 \mathrm{Ba}-\mathrm{Bd}$ ). It appears that curcumin is taken up by both cell lines displayed by fluorescence emitted from the accumulation of curcumin in the cytoplasm. In addition, the dark unstained nucleus shown in Figure 7 indicates that curcumin-loaded SMA did not interact with the nucleus.

Figure 8 shows the fluorescent images of curcuminloaded FA-DABA-SMA in RAW-Blue macrophage cells (Figure $8 \mathrm{Aa}-\mathrm{Ad}$ ) and $\mathrm{PANC1}$ pancreatic cancer cells (Figure $8 \mathrm{Ba}-\mathrm{Bd}$ ). It is observed for all four concentrations

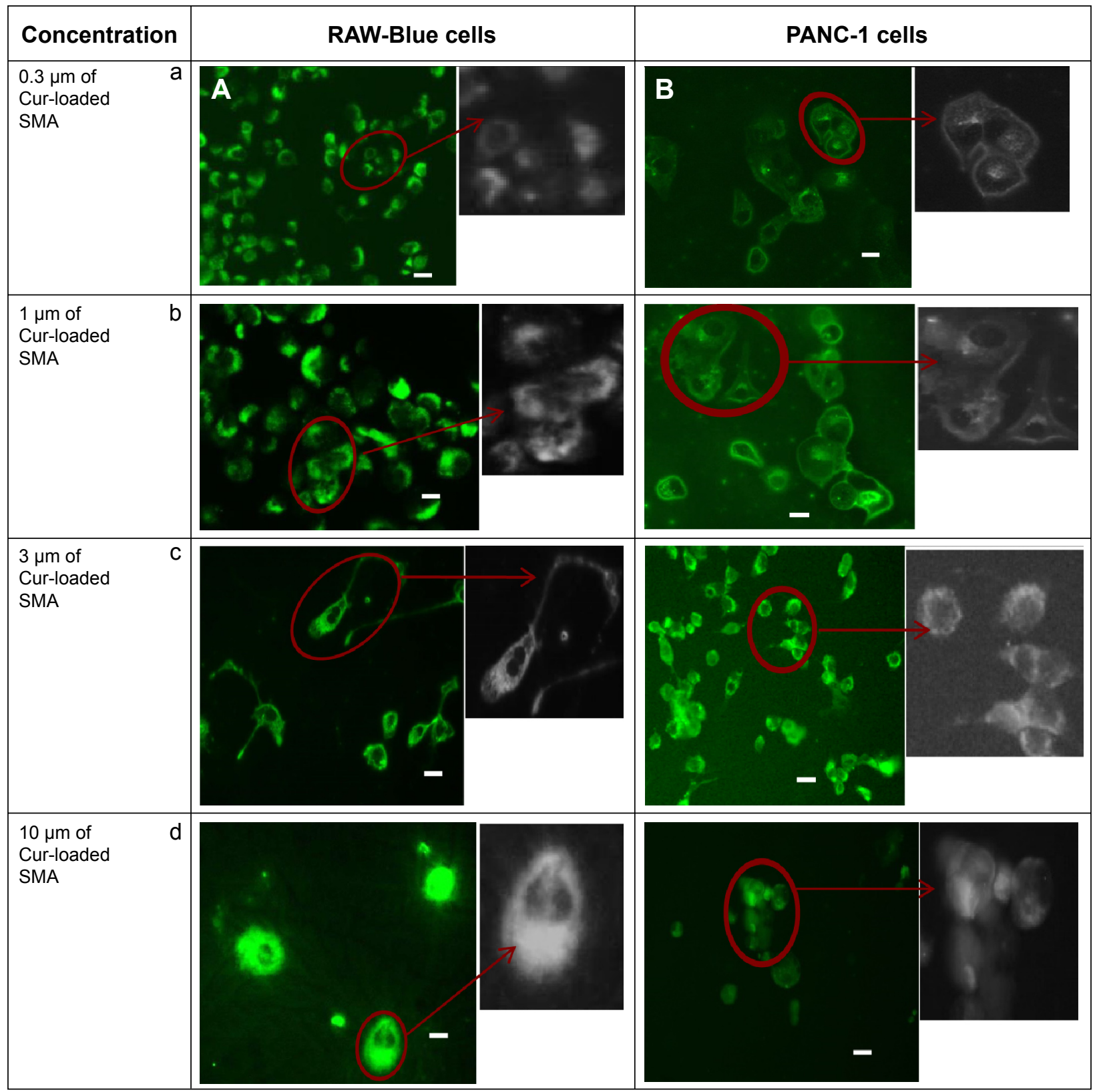

Figure 7 Fluorescent images showing cellular uptake of curcumin-loaded SMA in (A) RAW-Blue and (B) PANC-I cell lines.

Notes: Images in the left column indicate (A) RAW-Blue cell line with concentrations of (a) 0.3, (b) I, (c) 3, and (d) $10 \mu \mathrm{m}$ of curcumin-loaded SMA, respectively, and images in the right column indicate (B) PANC-I cell line with concentrations of (a) 0.3 , (b) I, (c) 3 , and (d) $10 \mu \mathrm{m}$ of curcumin-loaded SMA, respectively. The image bar scale represents $100 \mu \mathrm{m}$.

Abbreviations: SMA, poly(styrene-alt-maleic anhydride); Cur, curcumin. 


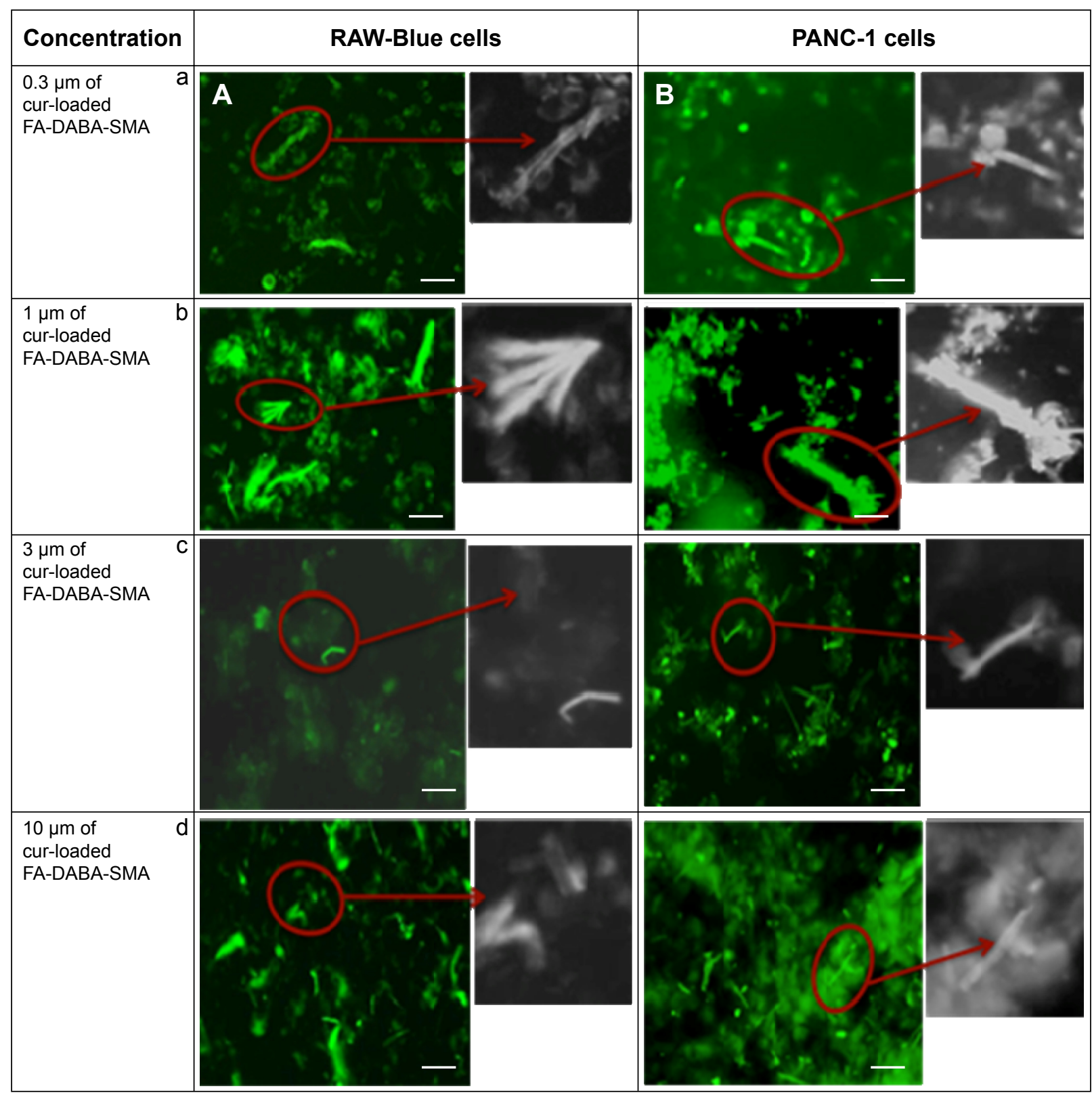

Figure 8 Fluorescent images showing cellular uptake of curcumin-loaded FA-DABA-SMA in (A) RAW-Blue and (B) PANC-I cell lines.

Notes: Images in the left column indicate (A) RAW-Blue cell line with concentrations of (a) 0.3, (b) I, (c) 3, and (d) $10 \mu \mathrm{m}$ of curcumin-loaded FA-DABA-SMA, respectively, and images in the right column indicate (B) PANC-I cell line with concentrations of (a) 0.3 , (b) I, (c) 3 , and (d) $10 \mu \mathrm{m}$ of curcumin-loaded FA-DABA-SMA, respectively. The image bar scale represents $100 \mu \mathrm{m}$.

Abbreviations: SMA, poly(styrene-alt-maleic anhydride); Cur, curcumin.

that the modified FA-DABA-SMA polymers are taken up by cells differently than pure SMA. At almost all concentrations, the polymer chain exhibits association around the cells into cylindrical filaments. This association is specific to cells as no association is observed when the polymer is not in contact with the cells. The enhanced fluorescent contrast at the filaments due to the curcumin inside the polymers confirms that the aggregation is formed by the FA-DABA-SMA polymers. Furthermore, the curcumin was taken up by both cell lines and was found to cross and agglomerate inside the nucleus and cytoplasm. Lastly, the morphological changes observed in the cells indicate that the cells are slowly losing their shapes, indicating the initiation of cell death. The exact mechanisms behind the polymer aggregation around cells are still under investigation; however, the enhanced fluorescent contrast in the filaments and the specificity toward cells exhibit great potential for enhanced delivery efficiency.

To exclude the possibility of toxicity from the polymeric template, we utilized empty nanoparticles (SMA and functionalized FA-DABA-SMA) treated PANC-1 cancer 


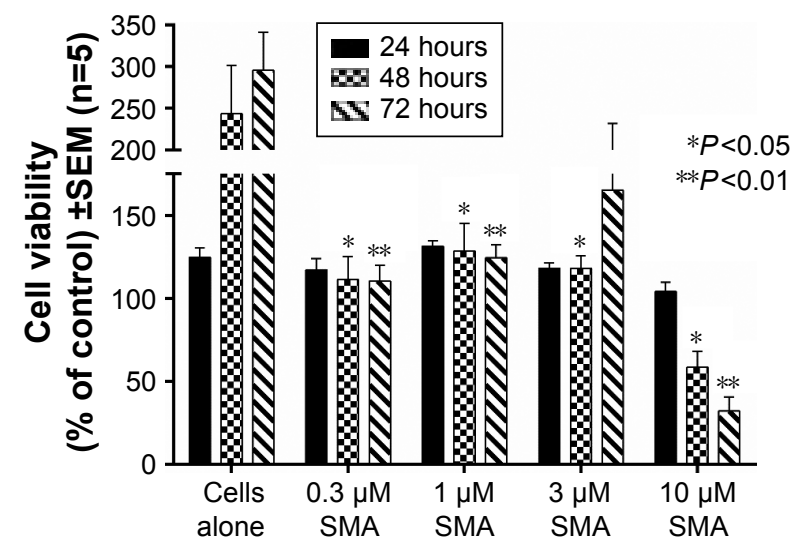

Figure 9 Viability of PANC-I cells treated with empty SMA at different doses using the WST-I assay.

Notes: The control is represented by the cells alone. Indicated $P$-values vs untreated cells alone $(n=5)$.

Abbreviations: SMA, poly(styrene-alt-maleic anhydride); SEM, standard error of mean.

cell line using WST-1 reagents (Figures 9 and 10). Four concentrations of SMA $(0.3,1,3$, and $10 \mu \mathrm{m})$ were tested, and the readings were taken at 24,48 , and 72 hours. The results shown in Figure 9 indicate that the SMA polymers do not exhibit strong toxicity on the cancer cells. However, the highest concentration of $10 \mu \mathrm{m}$ results in cell death at 48 and 72 hours, indicating that the toxicity of SMA is dosage dependent. As a result, the $10 \mu \mathrm{m}$ concentration of SMA was excluded from further testing. Empty FA-DABA-SMA

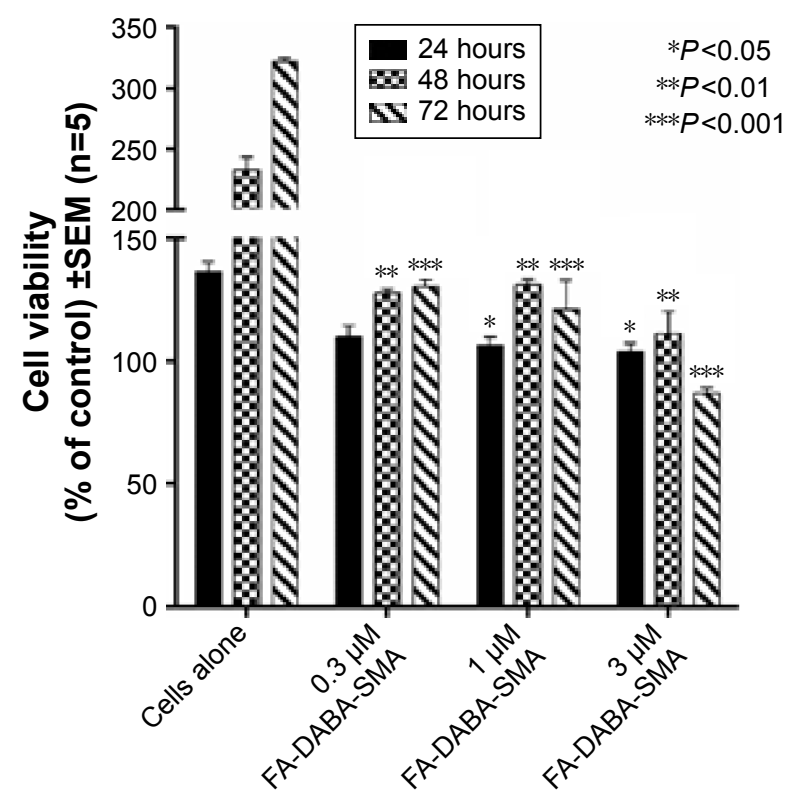

Figure 10 Viability of PANC-I cells treated with empty FA-DABA-SMA at different doses using the WST-I assay.

Notes: The control is represented by the cells alone. Indicated $P$-values vs untreated cells alone $(n=5)$.

Abbreviations: SMA, poly(styrene-alt-maleic anhydride); SEM, standard error of mean.

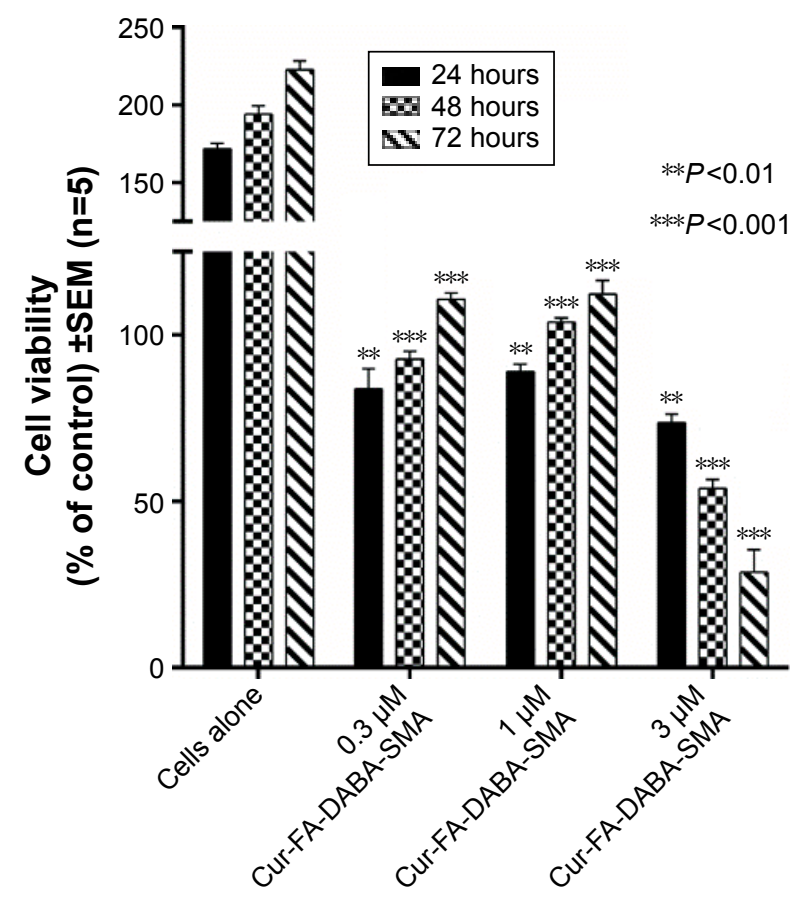

Figure I I Viability of PANC-I cells treated with Cur-encapsulated FA-DABA-SMA at different doses using the WST-I assay.

Notes: The control is represented by the cells alone. Indicated $P$-values vs untreated cells alone $(n=5)$.

Abbreviations: SMA, poly(styrene-alt-maleic anhydride); Cur, curcumin; SEM, standard error of mean.

was also tested against PANC- 1 at $0.3,1$, and $3 \mu \mathrm{m}$ concentrations. As shown in Figure 10, the empty functionalized FA-DABA-SMA delivery vehicle did not interfere with cell growth, and is therefore deemed nontoxic to the cells.

The effect of FA-DABA-SMA loaded with curcumin on PANC-1 cell viability was also investigated using the WST-1 assay at $0.3,1$, and $3 \mu \mathrm{m}$ concentrations (Figure 11). The results show that although the lower concentrations of curcumin (Cur)-loaded FA-DABA-SMA did not cause cell death, the $3 \mu \mathrm{m}$ Cur/FA-DABA-SMA demonstrate significant toxicity and cell death. The toxicity at $3 \mu \mathrm{m}$ after 72 hours of treatment, compared with empty SMA and FA-DABA-SMA, confirms the on-site release of curcumin by the FA-DABA-SMA delivery platform (Figure 12). The folic acid functionalized SMA polymers present enhanced delivery effects on tumor cells, which are consistent with the fluorescent microscopy results shown in Figure 8. Therefore, folic acid-conjugated amphiphilic alternating copolymer is a novel delivery platform for the delivery of hydrophobic chemotherapeutic agents against cancer cells.

\section{Conclusion}

In conclusion, this paper presents a very unique interaction of cell lines containing overly expressed folic acid receptors 


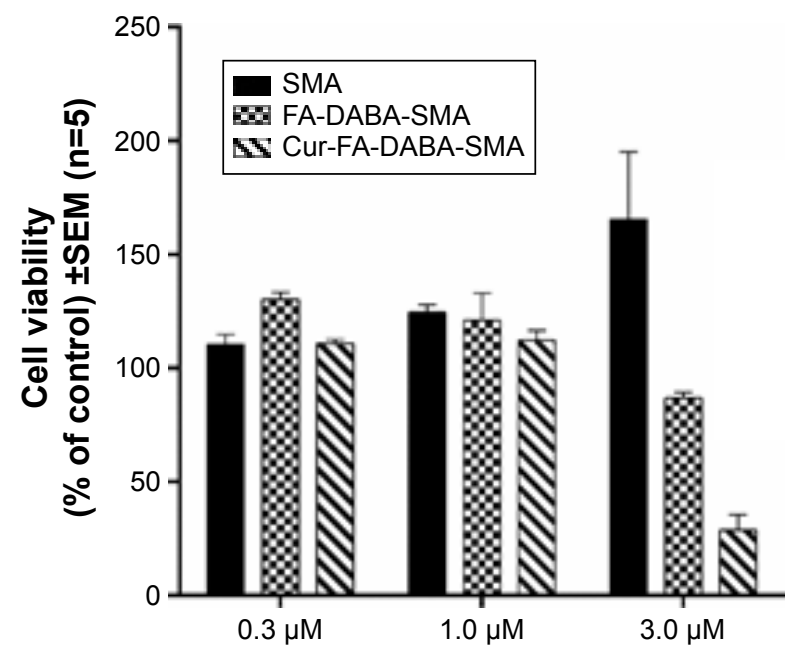

Figure 12 Comparison of viability of PANC-I cells at 72 hours treated with SMA, FA-DABA-SMA, and Cur-encapsulated FA-DABA-SMA at different doses using the WST-I assay $(n=5)$.

Abbreviations: SMA, poly(styrene-alt-maleic anhydride); Cur, curcumin; SEM, standard error of mean.

in contact with a newly developed targeted drug delivery vehicle. Cell viability assay showed that empty SMA and FA-DABA-SMA nanoparticles did not cause cell death, confirming the biocompatible properties of the delivery vehicles. The enhanced fluorescence microscopy showed the cellular uptake of FA-DABA-SMA loaded with curcumin by both PANC-1 and RAW-Blue cell lines. The drug carrier FADABA-SMA is shown to release the drug efficiently inside the nucleus and cytoplasm, initiating cell death. This study revealed that the novel interactions between the modified FADABA-SMA polymers with the cells could lead to enhanced hydrophobic drug delivery efficiency and could possibly be developed as a probe for cancer therapeutics.

With three levels of control including EPR effect, folic acid active targeting, and $\mathrm{pH}$ responsiveness in the cancer cell microenvironment, FA-DABA-SMA polymers show promise as a new active tumor targeting drug delivery system.

More studies are being undertaken to investigate the encapsulation and release profiles of curcumin encapsulated in SMA and FA-DABA-SMA. In addition, clinical conventional approved anticancer drugs will be loaded and tested in these polymers to study the solubility, cellular uptake, and cytotoxicity.

\section{Acknowledgments}

This work was supported in part by grants to C MalardierJugroot and M R Szewczuk from the Natural Sciences and Engineering Research Council of Canada. Xia Li is the recipient of the Alexander Graham Bell Canada Graduate
Scholarship from Natural Sciences and Engineering Research Council of Canada.

\section{Disclosure}

The authors report no conflicts of interest in this work.

\section{References}

1. Chidambaram M, Manavalan R, Kathiresan K. Nanotherapeutics to overcome conventional cancer chemotherapy limitations. $J$ Pharm Pharm Sci. 2011;14(1):67-77.

2. Bertrand N, Wu J, Xu X, Kamaly N, Farokhzad OC. Cancer nanotechnology: the impact of passive and active targeting in the era of modern cancer biology. Adv Drug Deliv Rev. 2014;66:2-25.

3. Brannon-Peppas L, Blanchette JO. Nanoparticle and targeted systems for cancer therapy. Adv Drug Deliv Rev. 2012;64:206-212.

4. Bae YH, Park K. Targeted drug delivery to tumors: myths, reality and possibility. J Controlled Release. 2011;153(3):198-205.

5. Malardier-Jugroot C, van de Ven TG, Cosgrove T, Richardson RM, Whitehead MA. Novel self-assembly of amphiphilic copolymers into nanotubes: characterization by small-angle neutron scattering. Langmuir. 2005;21(22):10179-10187.

6. Malardier-Jugroot C, van de Ven TG, Whitehead MA. Linear conformation of poly(styrene-alt-maleic anhydride) capable of self-assembly: a result of chain stiffening by internal hydrogen bonds. J Phys Chem B. 2005;109(15):7022-7032.

7. Maeda H, Nakamura H, Fang J. The EPR effect for macromolecular drug delivery to solid tumors: improvement of tumor uptake, lowering of systemic toxicity, and distinct tumor imaging in vivo. Adv Drug Deliv Rev. 2013;65(1):71-79.

8. Zhang Y, Chan HF, Leong KW. Advanced materials and processing for drug delivery: the past and the future. Adv Drug Deliv Rev. 2013;65(1):104-120.

9. Allen TM, Cullis PR. Drug delivery systems: entering the mainstream. Science. 2004;303(5665):1818-1822.

10. Maeda H. SMANCS and polymer-conjugated macromolecular drugs: advantages in cancer chemotherapy. Adv Drug Deliv Rev. 1991;6(2): 181-202.

11. Brown SD, Nativo P, Smith JA, et al. Gold nanoparticles for the improved anticancer drug delivery of the active component of oxaliplatin. J Am Chem Soc. 2010;132(13):4678-4684.

12. Rejinold NS, Thomas RG, Muthiah M, et al. Radio frequency triggered curcumin delivery from thermo and $\mathrm{pH}$ responsive nanoparticles containing gold nanoparticles and its in vivo localization studies in an orthotopic breast tumor model. RSC Adv. 2014;4(74):39408.

13. Gao W, Chan JM, Farokhzad OC. pH-responsive nanoparticles for drug delivery. Mol Pharm. 2010;7(6):1913-1920.

14. Henry SM, El-Sayed ME, Pirie CM, Hoffman AS, Stayton PS. pHresponsive poly(styrene- alt-maleic anhydride) alkylamide copolymers for intracellular drug delivery. Biomacromolecules. 2006;7(8):2407-2414.

15. Lale SV, Aswathy RG, Aravind A, Kumar DS, Koul V. AS1411 aptamer and folic acid functionalized $\mathrm{pH}-$ responsive ATRP fabricated pPEGMA-PCL-pPEGMA polymeric nanoparticles for targeted drug delivery in cancer therapy. Biomacromolecules. 2014;15(5):1737-1752.

16. Li X, McTaggart M, Malardier-Jugroot C. Synthesis and characterization of a $\mathrm{pH}$ responsive folic acid functionalized polymeric drug delivery system. Biophy Chem. 2016;214-215:17-26.

17. Matini, T., Francini, N., Battocchio, A., et al. Synthesis and characterization of variable conformation $\mathrm{pH}$ responsive block co-polymers for nucleic acid delivery and targeted cell entry. Polym Chem. 2014;5:1626-1636.

18. Lee RJ, Low PS. Delivery of liposomes into cultured KB cells via folate receptor-mediated endocytosis. J Biol Chem. 1994;269(5): 3198-3204.

19. Kim SL, Jeong HJ, Kim EM, Lee CM, Kwon TH, Sohn MH. Folate receptor targeted imaging using poly(ethylene glycol)-folate: in vitro and in vivo studies. J Korean Med Sci. 2007;22(3):405-411. 
20. Sudimack J, Lee RJ. Targeted drug delivery via the folate receptor. $A d v$ Drug Deliv Rev. 2000;41(2):147-162.

21. Antony AC. The biological chemistry of folate receptors. Blood. 1992; 79(11):2807-2820.

22. Bhattacharya D, Das M, Mishra D, et al. Folate receptor targeted, carboxymethyl chitosan functionalized iron oxide nanoparticles: a novel ultradispersed nanoconjugates for bimodal imaging. Nanoscale. 2011; 3(4): 1653.

23. Aggarwal BB, Surh YJ, Shishodia S. The Molecular Targets and Therapeutic Uses of Curcumin in Health and Disease. New York, NY: Springer; 2007.

24. López-Lázaro M. Anticancer and carcinogenic properties of curcumin: considerations for its clinical development as a cancer chemopreventive and chemotherapeutic agent. Mol Nutr Food Res. 2008;52(Suppl 1): S103-S127.

25. Kunwar A, Barik A, Mishra B, Rathinasamy K, Pandey R, Priyadarsini KI. Quantitative cellular uptake, localization and cytotoxicity of curcumin in normal and tumor cells. Biochim Biophys Acta BBA - Gen Subj. 2008;1780(4):673-679.

26. Chang PY, Peng SF, Lee CY. Curcumin-loaded nanoparticles induce apoptotic cell death through regulation of the function of MDR1 and reactive oxygen species in cisplatin-resistant CAR human oral cancer cells. Int J Oncol. 2013;43(4):1141-1150.

27. Shehzad A, Lee J, Huh TL, Lee YS. Curcumin induces apoptosis in human colorectal carcinoma (HCT-15) cells by regulating expression of Prp4 and p53. Mol Cells. 2013;35(6):526-532.

28. Das M, Sahoo SK. Folate decorated dual drug loaded nanoparticle: role of curcumin in enhancing therapeutic potential of nutlin-3a by reversing multidrug resistance. PLoS One. 2012;7(3):e32920.

29. Bisht S, Feldmann G, Soni S, et al. Polymeric nanoparticle-encapsulated curcumin ("nanocurcumin"): a novel strategy for human cancer therapy. J Nanobiotechnology. 2007;5(1):3.

30. Adhikary R, Carlson PJ, Kee TW, Petrich JW. Excited-state intramolecular hydrogen atom transfer of curcumin in surfactant micelles. J Phys Chem B. 2010;114(8):2997-3004.

31. Puvvada N, Rajput S, Kumar BN, Mandal M, Pathak A. Exploring the fluorescence switching phenomenon of curcumin encapsulated niosomes: in vitro real time monitoring of curcumin release to cancer cells. RSC Adv. 2013;3(8):2553.

32. Chignell CF, Bilskj P, Reszka KJ, Motten AG, Sik RH, Dahl TA. Spectral and photochemical properties of curcumin. Photochem Photobiol. 1994;59(3):295-302.

33. Patra D, Barakat C. Synchronous fluorescence spectroscopic study of solvatochromic curcumin dye. Spectrochim Acta A Mol Biomol Spectrosc. 2011;79(5):1034-1041.
34. Zhao Z, Xie M, Li Y, et al. Formation of curcumin nanoparticles via solution-enhanced dispersion by supercritical CO2. Int J Nanomedicine. 2015:10:3171-3181.

35. Xie M, Fan D, Chen Y, et al. An implantable and controlled drug-release silk fibroin nanofibrous matrix to advance the treatment of solid tumour cancers. Biomaterials. 2016;103:33-43.

36. Huang Q, Zhang L, Sun X, Zeng K, Li J, Liu YN. Coating of carboxymethyl dextran on liposomal curcumin to improve the anticancer activity. RSC Adv. 2014;4(103):59211-59217.

37. Taurin S, Nehoff H, Diong J, Larsen L, Rosengren RJ, Greish K. Curcumin-derivative nanomicelles for the treatment of triple negative breast cancer. J Drug Target. 2013;21(7):675-683.

38. Sanoj Rejinold N, Muthunarayanan M, Divyarani VV, et al. Curcuminloaded biocompatible thermoresponsive polymeric nanoparticles for cancer drug delivery. J Colloid Interface Sci. 2011;360(1):39-51.

39. Gou M, Men K, Shi H, et al. Curcumin-loaded biodegradable polymeric micelles for colon cancer therapy in vitro and in vivo. Nanoscale. 2011;3(4):1558.

40. Koley P, Pramanik A. Multilayer vesicles, tubes, various porous structures and organo gels through the solvent-assisted self-assembly of two modified tripeptides and their different applications. Soft Matter. 2012;8(19):5364.

41. Doane T, Burda C. Nanoparticle mediated non-covalent drug delivery. Adv Drug Deliv Rev. 2013;65(5):607-621.

42. Yang C, Attia AB, Tan JP, et al. The role of non-covalent interactions in anticancer drug loading and kinetic stability of polymeric micelles. Biomaterials. 2012;33(10):2971-2979.

43. Ngamwongsatit P, Banada PP, Panbangred W, Bhunia AK. WST1-based cell cytotoxicity assay as a substitute for MTT-based assay for rapid detection of toxigenic Bacillus species using $\mathrm{CHO}$ cell line. J Microbiol Methods. 2008;73(3):211-215.

44. Tan AS, Berridge MV. Superoxide produced by activated neutrophils efficiently reduces the tetrazolium salt, WST-1 to produce a soluble formazan: a simple colorimetric assay for measuring respiratory burst activation and for screening anti-inflammatory agents. J Immunol Methods. 2000;238(1-2):59-68.

45. Malardier-Jugroot C, van de Ven TGM, Whitehead MA. Characterization of a novel self-association of an alternating copolymer into nanotubes in solution. Mol Simul. 2005;31(2-1):173-178.

46. McTaggart M, Malardier-Jugroot C, Jugroot M. Self-assembled biomimetic nanoreactors I: polymeric template. Chem Phys Lett. 2015;636: 216-220.
Drug Design, Development and Therapy

\section{Publish your work in this journal}

Drug Design, Development and Therapy is an international, peerreviewed open-access journal that spans the spectrum of drug design and development through to clinical applications. Clinical outcomes, patient safety, and programs for the development and effective, safe, and sustained use of medicines are the features of the journal, which

\section{Dovepress}

has also been accepted for indexing on PubMed Central. The manuscript management system is completely online and includes a very quick and fair peer-review system, which is all easy to use. Visit http://www.dovepress.com/testimonials.php to read real quotes from published authors. 